\title{
In vivo validation of an ultra-high field, high temporal resolution myocardial tagging technique for assessment of diastolic function in mice
}

\author{
Jaehoon Chung ${ }^{*}$, Hong Liu, Euy-Myoung Jeong, Lianzhi Gu, Scott Gladstein, Afshin Farzaneh-Far, \\ E Douglas Lewandowski, Samuel Dudley
}

From 16th Annual SCMR Scientific Sessions

San Francisco, CA, USA. 31 January - 3 February 2013

\section{Background}

Heart failure with preserved ejection fraction accounts for approximately half of all heart failure cases and is associated with similar morbidity and mortality. Although abnormalities of diastolic function are felt to play an important role, no specific treatments have been identified for this common condition, primarily because of poor understanding of its pathophysiology. Despite development of several murine models of this disease, accurate non-invasive assessment of diastolic function has been challenging. Echocardiographic measurements have been limited by small heart sizes, rapid ventricular rates and high inter-observer variability. The aim of this study was to assess the ability of ultra-high field, high temporal resolution CMR tagging to assess diastolic function in mice, compared to the gold-standard technique of invasive pressure-volume loop analysis.

\section{Methods}

High fat diet-induced diabetic mice $(\mathrm{n}=7)$ and agematched control mice $(\mathrm{n}=4)$ underwent tissue tagged CMR using a 14.1-Tesla, $89 \mathrm{~mm}$ vertical bore magnet with a $600 \mathrm{MHz}$ birdcage resonator. Myocardial tagged images were obtained at the mid-ventricular short axis from endsystole to end-diastole using a spatial modulation of magnetization (SPAMM) sequence (Figure 1A and B). Tagged images were processed using a Matlab-based program to calculate maximal circumferential strain (Ecc) rate (Figure 1C, D and E). Concurrent invasive pressure-volume loop analysis was performed within 24 hours using $1.4 \mathrm{Fr}$ pressure-volume catheters. The end-diastolic pressure volume relationship (EDPVR) was calculated by acquiring pressure-volume loops following acute compression of the inferior vena cava.

\section{Results}

LV ejection fraction was similar in both groups $(65.8 \pm$ $1.8 \%$ vs. $65.3 \pm 1.6 \%$, p=0.86). However, Ecc rate was significantly reduced in diabetic mice compared with controls $(4.24 \pm 0.281 / \mathrm{s}$ vs. $5.94 \pm 0.191 / \mathrm{s}, \mathrm{p}<0.01)$, indicating significant relaxation impairment during the rapid filling phase in diabetic mice (Figure 2A). Pressure-volume loop analysis showed that diabetic mice had a significantly steeper EDPVR compared with controls $(0.38 \pm 0.04$ vs. $0.21 \pm 0.03, \mathrm{p}<0.05)$, confirming diastolic dysfunction in the diabetic mice (Figure 2B). There was a significant correlation between Ecc rate and EDPVR $(r 2=0.65, \mathrm{p}<0.01$, Figure $2 \mathrm{C})$.

\section{Conclusions}

This study provides preliminary validation of ultra-high field, high temporal resolution CMR tagging for non-invasive assessment of diastolic function in mice compared to the gold standard of invasive pressure-volume loop analysis. This technique has potential for assessing the effects of putative therapeutic compounds on mice models of diastolic dysfunction.

\section{Funding}

This work was supported by NIH R01 and T32.

University of Illinois at Chicago, Chicago, IL, USA

@ 2013 Chung et al; licensee BioMed Central Ltd. This is an Open Access article distributed under the terms of the Creative Commons Attribution License (http://creativecommons.org/licenses/by/2.0), which permits unrestricted use, distribution, and reproduction in any medium, provided the original work is properly cited. 


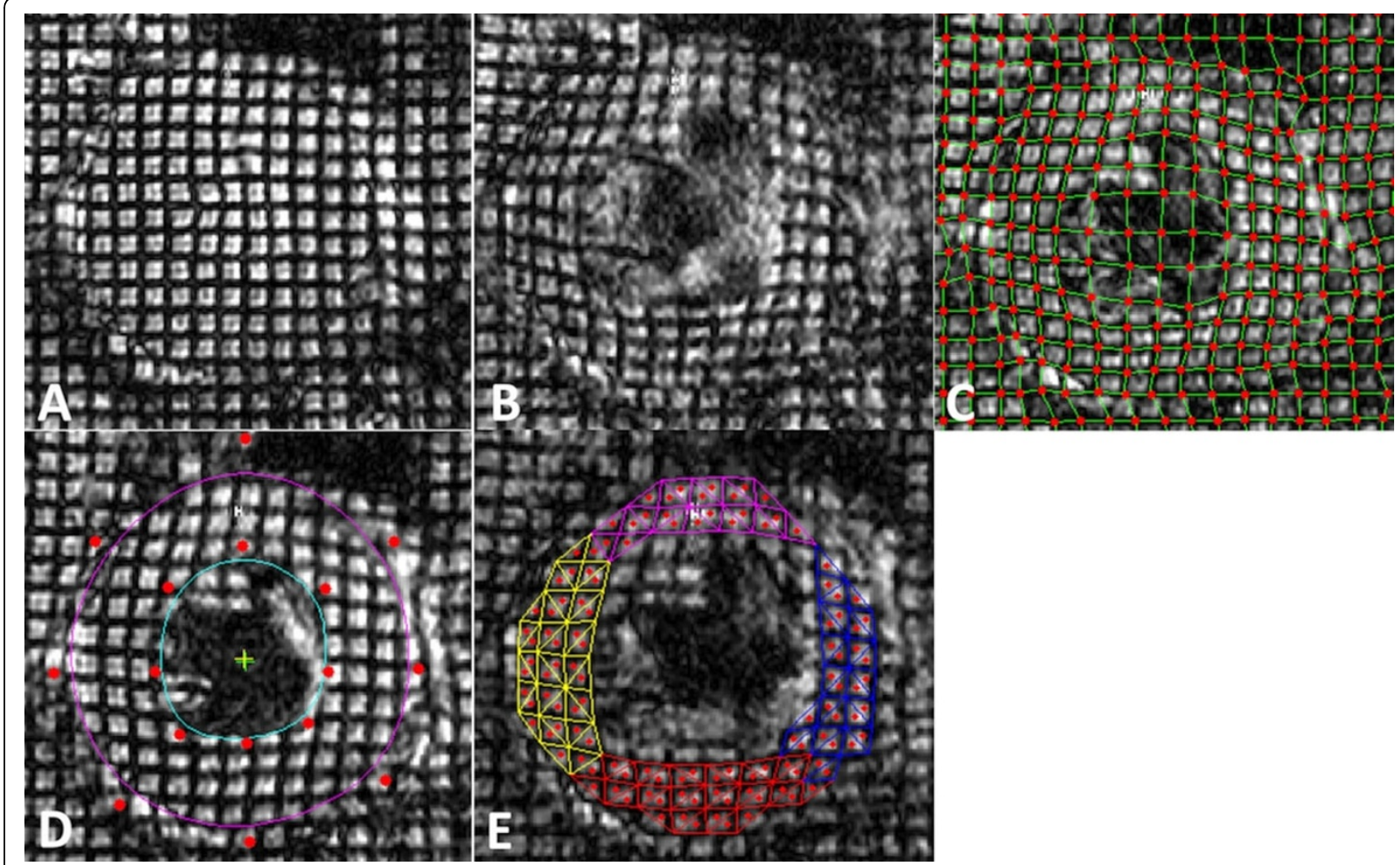

Figure 1 Homogeneous strain analysis of myocardial tagged images. Cardiac and respiratory gated SPAMM-tagged images were obtained at the mid-ventricular short axis from end-systole (A) to end-diastole (B) with the following parameters: FOV $20 \mathrm{~mm}$, slice thickness $1 \mathrm{~mm}$, echo time $1.5 \mathrm{~ms}$, temporal resolution $5 \mathrm{~ms}$, flip angle 30 degrees, acquisition matrix 256x256, number of excitations=4. Each tagged image was overlaid with manually traced tagged lines and intersections (C). Endo- and epicardium was contoured using the B spline method to define the direction of circumferential and radial strain at 8 different points as indicated by red dots (D). Triangulation of myocardium allowed diastolic homogeneous strain analysis and calculation of circumferential strain (ECC) rate (E).

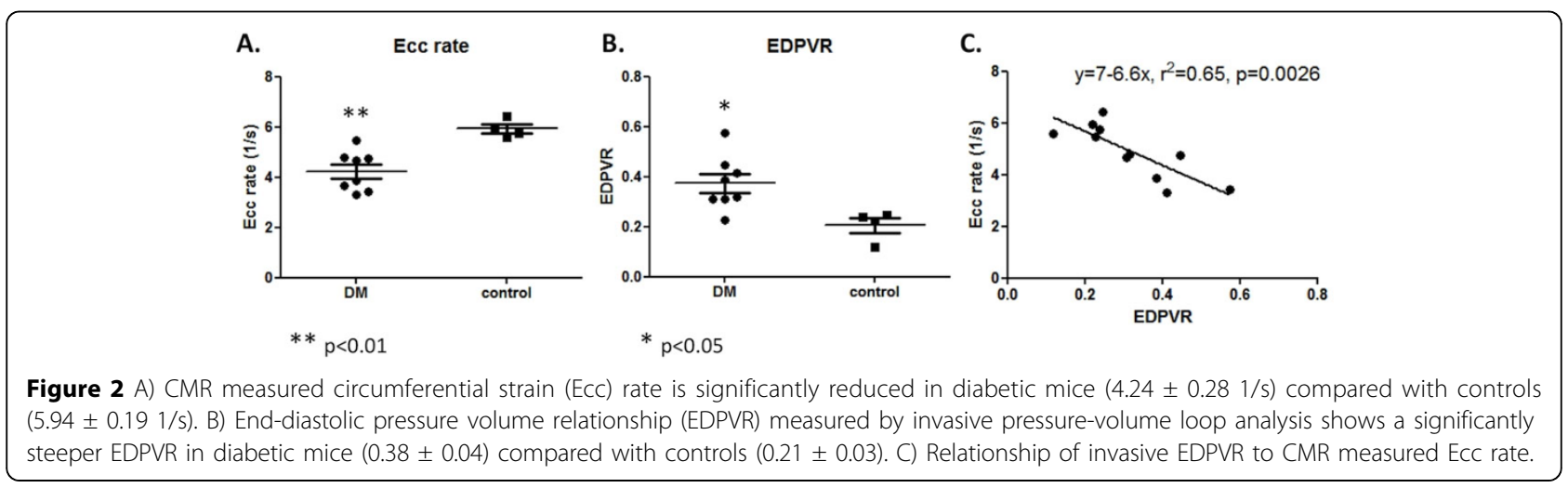

Published: 30 January 2013

doi:10.1186/1532-429X-15-S1-P129

Cite this article as: Chung et al:: In vivo validation of an ultra-high field, high temporal resolution myocardial tagging technique for assessment of diastolic function in mice. Journal of Cardiovascular Magnetic Resonance 2013 15(Suppl 1):P129. 